\title{
Prevalence of psychopathic traits in a large sample of Polish adolescents from rural and urban areas
}

\author{
Lidia Perenc ${ }^{1}$, Mieczysław Radochoński² \\ ${ }^{1}$ Faculty of Medicine, University of Rzeszow, Poland \\ ${ }^{2}$ Faculty of Education, University of Rzeszow, Poland
}

Perenc L, Radochoński M. Prevalence of psychopathic traits in a large sample of Polish adolescents from rural and urban areas. Ann Agric Environ Med. 2016; 23(2): 368-372. doi: 10.5604/12321966.1203907

\section{Abstract}

Objective. The primary aim of the study was to assess the prevalence of psychopathic traits in a large sample of Polish adolescents representing both the rural and urban social milieu. An additional aim was to compare the results with similar studies conducted in other countries.

Materials and method. The study was conducted on a sample of 9,415 secondary school students (4,808 boys, 4,607 girls) aged 13 - 16. Psychopathic traits were measured by teacher-report ratings with the Antisocial Process Screening Device scale (APSD).

Results and conclusions. Only a marginal part of the Polish adolescents demonstrated clinically significant symptoms of psychopathic disorder ( $\mathrm{N}=253 ; 2.68 \%$ ). There was a statistically significant difference between subjects from the rural (2.12\%) and urban (3.45\%) social milieu. Respective comparison showed that Polish youngsters scored much lower on total psychopathy scores than Chinese (Hong Kong) and American adolescents. The authors encourage replication of this research in other East European countries.

\section{- Key words \\ psychopathic traits, adolescents, rural social milieu, prevalence}

\section{INTRODUCTION}

Psychopathy is currently viewed as a personality disorder characterized by a constellation of interpersonal, affective and behavioural characteristics. Early concepts of psychopathy suggested that it was a one-dimensional disorder, but contemporary studies propose that it has a three-factor structure: 1) an arrogant, deceitful interpersonal style involving dishonesty, manipulation, grandiosity, and glibness, 2) defective emotional experience involving poor empathy, lack of remorse, shallow emotions, and lack of responsibility for one's own actions, 3) behavioural manifestations of impulsiveness, irresponsibility and sensation-seeking [1].

Until about three decades ago, relatively little attention was devoted to the evidence of psychopathic traits in children and adolescents. Most of the studies on the prevalence, etiology and symptoms of psychopathy were conducted in adult populations. Psychopaths were described as callousunemotional individuals, aware of their wrongdoings but lacked remorse and guilt. They were also viewed as individuals who fail to accept responsibility for their actions, and at the same time, are proud to be able to avoid punishment. Some psychopaths possess superficial charm which they use to manipulate other people. Additionally, they have the ability to lie with remarkable conviction and they are usually unreliable. Their intelligence is typically average to above-average. Since psychopaths do not suffer from a distorted sense of reality, and since they are rational and aware of their actions, mental health professionals classify them as sane [2].

Address for correspondence: Mieczysław Radochoński, Faculty of Education, University of Rzeszow, Rzeszow, Jałowego 24, 35-959 Rzeszów, Poland

E-mail: mieczrad@univ.rzeszow.pl

Received: 14 April 2014; accepted: 19 June 2014
For the last two decades a growing number of studies on psychopathy have focused on children and adolescents. The aim of many of these studies was to understand the etiology and developmental factors underlying a constellation of traits. Mental health researchers tried to determine specific factors influencing the development of psychopathic traits in the early stages of life. Some were inclined to argue that psychopathy is related to parenting styles and that children who come from pathological families are more prone to psychopathic disorder [3]. This assumption was true to some extent because the presence of such factors as parental alcoholism, antisocial style of life, inconsistent discipline, and lack of supervision are related to psychopathy. However, it is also true that there are a large number of psychopaths who were raised in nurturing and loving family environment [2]. These observations lead to the conclusion that the development of psychopathy does not only depend on environmental factors, but that there must be other factors that come into play. Recent research has acknowledged that there is a genetic factor that is clearly associated with the development of psychopathy. Moreover, when individuals with certain genetic predisposition are placed in a noxious environment, genetic factors may play an important role in determining the probability that those individuals will learn an antisocial style of life [4]. In other words, individuals with psychopathy are neurobiologically different from nonpsychopathic persons, and these differences are responsible for the different influence of the social environment.

Research suggests that psychopathy does not emerge suddenly in early adulthood, instead, it develops gradually throughout childhood and adolescence. Individual histories of adults with psychopathy usually include an early onset of this disorder, often with severe and permanent dysfunction [5]. Many children and adolescents with psychopathic traits 
exhibit serious behavioural problems, e.g. theft, aggression, drug abuse, truancy, lying, and poor school performance. Nevertheless, not all children who manifest psychopathic traits go on to commit crimes in adult age, which suggests that only a proportion of psychopaths are criminals, some disturbed behaviours change with time, and some therapeutic intervention may help to change undesired behaviour. Studies suggest that the prevalence of psychopathy in adolescents is higher than in adult populations, which highlights an issue of stability of the disorder over time [6]. For example, Forth and Burke [7] found that 3.5\% of young people in community care were psychopathic, and $12 \%$ of those on probation and $28 \%$ of those in prisons. On the other hand, Brandt et al. [8] found that the prevalence of psychopathy in a group of incarcerated adolescents was $37 \%$. The estimated prevalence of adult psychopathy in the general population is about $1 \%$, rising to between $15 \%-25 \%$ in incarcerated groups. There are higher rates (50-80\%) of antisocial personality disorder in prison populations, but only $20 \%$ of these meet Hare's criteria for psychopathy [9]. A survey performed by Coid et al. [10] demonstrated that psychopathy is rare, affecting less than $1 \%$ of the household population, although it is common among prisoners, homeless persons, and psychiatric admissions. There is a half-normal distribution of psychopathic traits in the general population, with the majority having no traits, a significant proportion with non-zero values, and a severe subgroup of persons with multiple associated social and behavioural problems. This distribution has implications for research into the etiology of psychopathy and its consequences for society.

\section{OBJECTIVE}

The aim of the presented study is to evaluate the prevalence of psychopathic traits in the general population of adolescents aged 13 - 16 years, representing the rural and urban environments. In Poland, there has been very little research on this issues, especially with regard to the social backgrounds of adolescents. For example, some researchers, such as Frick and Hare [11], have argued that many more studies need to be performed in order to establish psychometric properties, and the practical utility of the measurements used in the assessment of psychopathic traits in different racial and ethnic groups. Such studies have been performed for a few decades in the USA, Canada, and some West European countries. Poland does not belong to this group. In this context, the purpose of this current study is to fill this gap on ethnicity research by assessing the prevalence of psychopathic disorders in a very large community sample of adolescents in Poland. For example, similar studies were performed in Austria and Germany, but they included relatively small populations [12].

The first hypothesis for the current study was that the prevalence of psychopathic traits in a large mainstream sample of Polish adolescents would not differ significantly from the results of similar research conducted in other countries. The second hypothesis was that the social environment, i.e. rural vs. urban, is a factor which significantly influences the prevalence of psychopathic traits in the studied group.

\section{MATERIALS AND METHOD}

This large-scale cross-sectional study included a total sample of 9,415 students from 142 secondary schools (gymnasiums) located in the Podkarpackie Province in the extreme southeastern corner of Poland. The participating schools were randomly selected from a total of over 500 secondary schools functioning in the province at the time of the study. The students being assessed made up 9.5\% of the total population of students attending secondary schools, which totalled approximating 100,000 persons. The studied sample represented a relatively homogenous student population in terms of ethnicity, socio-economic status, and religious affiliation (about 95\% were Polish and Roman Catholic). The age of the students ranged between 13 - 16 years, mean age 14.38 years $(\mathrm{SD}=2.1)$. Among 9,415 students there were 4,607 girls (48.9\%) and 4,808 boys (51.1\%). Rural youth represented $42.43 \%$ of the studied group. The basic socio-demographic characteristics of the subjects are presented in Table 1.

Table 1. Socio-demographic characteristics of participants

\begin{tabular}{|c|c|c|c|c|c|}
\hline Age & 13 & 14 & 15 & 16 & Total \\
\hline $\mathrm{N}$ & 2889 & 3038 & 3179 & 208 & 9415 \\
\hline$\%$ & 31.74 & 32.26 & 33.76 & 2.24 & 100.00 \\
\hline Gender & \multicolumn{2}{|c|}{ Girls } & \multicolumn{2}{|c|}{ Boys } & Total \\
\hline $\mathrm{N}$ & \multicolumn{2}{|c|}{4607} & \multicolumn{2}{|c|}{4808} & 9415 \\
\hline$\%$ & \multicolumn{2}{|c|}{48.93} & \multicolumn{2}{|c|}{51.06} & 100.00 \\
\hline Social milieu & \multicolumn{2}{|c|}{ Urban } & \multicolumn{2}{|c|}{ Rural } & Total \\
\hline $\mathrm{N}$ & \multicolumn{2}{|c|}{3994} & \multicolumn{2}{|c|}{5421} & 9415 \\
\hline$\%$ & \multicolumn{2}{|c|}{57.57} & \multicolumn{2}{|c|}{42.43} & 100.00 \\
\hline Class (grade) & $\mathrm{I}^{\mathrm{st}}$ & & $I^{\text {nd }}$ & $\mathrm{III}^{\mathrm{rd}}$ & Total \\
\hline $\mathrm{N}$ & 307 & & 3023 & 3314 & 9415 \\
\hline$\%$ & 32.6 & & 32.11 & 35.22 & 100.00 \\
\hline
\end{tabular}

Measurments. The basic measure used in this study was the Antisocial Process Screening Device (APSD) - teachers' version [10]. The ASPD is a 20 -item measure belonging to the most widely-used scales of psychopathic traits in children and adolescents [13]. Originally known as the Psychopathy Screening Device, it was modeled after the PCL-R scale [2]. The items belonging to ASPD assess 3 different dimensions: 1) callous/unemotional (CU), 2) narcissism (N), and 3) impulsivity (I). High scores on these scales indicate high intensity for each particular trait. The items are graded on a 3-point scale: 0 - not at all true, 1 - sometimes true, 2 definitely true. Among 20 APSD items, 5 score inversely (2, $7,12,18$ and 20). The APSD can be completed by the child's parent/guardian or teacher. There is also a child self-report version of the APSD. In the USA, the APSD was normalized in a population of 1,120 schoolchildren whose mean age was 10.1 years. The results of statistical analyses showed a satisfactory level of internal consistency [11]. Previous studies with older children and adolescents also suggested that the teacher-report version used in the assessment of psychopathic traits was significantly more valid than parent-report version [14]. This supports the assumption that the APSD can be used as a reliable measure of psychopathic traits in younger adolescents in the school setting.

Internal consistency reported for the APSD in a community sample has been adequate for a total score of.78 -.81, but has 
been less desirable for factor scores, ranging from. $50-.68$ [15]. Nevertheless, the APSD is the most widely-used and researched brief psychopathy measure in the USA and other countries $[16,17]$. There is still no standard cut-off score recommended for the APSD which would allow categorical comparisons of psychopathic traits and classification of participants into high and low ratings. However, some researchers use a cut-off score of 20 [18], while others use a cut-off score of 25 [19]. Also, some researchers use a median-split [20]. In this study, the cut-off score of 25 was used to indicate high intensity of psychopathic traits. For theoretical reasons, in addition to using the total APSD score, researchers often use the callous-unemotional subscale score to distinguish a sub-sample of high-scoring children who have been shown to be more severe and persistent in their psychopathic behavior, compared with low scorers on the callous-unemotional subscale. Therefore, in the presented study, both the total APSD and the callous-unemotional subscale score for analyses were used. Binary variables (high/ low) were created by grouping subjects into 2 groups using the cut-off score of 25 . Rather than imposing a categorical distribution on the sample, the whole range of the APSD was used in the study in order to retain as much information from the scale as possible. The current study used the Polish translation of the original instrument; the English version of the questionnaire was adapted and translated according to guidelines widely-accepted for the successful translation of instruments in cross-cultural research [21].

Method. Final approval to conduct the research was obtained from the Provincial Education Authority (Podkarpackie Kuratorium Oświaty) in Rzeszow. Additionally, permission to perform the study was given by the principals of the 142 selected schools and parents' committees. All parents provided informed consent. The researchers discussed the aim of the study with the respective school principals and then sought their permission to invite teachers to participate. After agreement by the principals and parents' committees, detailed information related to the study instruments was given to the 426 teachers participating in the study. The persons in charge of data collection were teachers tutoring the group of students belonging to the class randomly selected to the study. These teachers knew the children best, in comparison to other teachers, and were therefore asked to complete the questionnaires assessing the childrens' psychopathic traits. The nominated teachers were initially trained during a special meetings organized at different locations in the Podkarpackie Province (i.e. Rzeszów, Przemyśl, Krosno, Tarnobrzeg), where they learned how to administer the measures. The participating teachers were asked to complete the questionnaire with reference to each student separately. Additionally, the socio-demographic data were collected completely anonymously. Every participant was were ensured that all information obtained would be confidential, securely stored, and used only for scientific purposes. All copies of the teachers' version of the questionnaire were taken by the researchers for quantitative analysis. The data collection took place in the schools after class hours. The teachers were not compensated financially.

\section{RESULTS}

The presented study examined the prevalence of clinicallysignificant psychopathic traits among students of secondary schools, and the relationships between psychopathic features and social environment. Descriptive statistics were calculated using SPSS version 18.0. A part of the results of this survey has already been shown in a previous report by the authors of the presented study, published in 2013 [22].

The study was performed in accordance with the Ethical Code of the University of Rzeszow.

Table 2. Differences in APSD scores according to gender and social milieu (results of $t$ test analysis)

\begin{tabular}{|c|c|c|c|c|c|c|c|}
\hline \multirow{2}{*}{$\begin{array}{l}\text { Psychopathic traits } \\
(\mathrm{N}=9.15)\end{array}$} & \multirow{2}{*}{ Mean $^{\mathrm{a}}$} & \multirow{2}{*}{$S D$} & \multicolumn{2}{|c|}{ Mean } & \multicolumn{2}{|c|}{ Mean } & \multirow{2}{*}{$p$} \\
\hline & & & Boys $s^{b}$ & Girlsc & Urban $^{\text {d }}$ & Rurale & \\
\hline Callous/unemotional (CU) & 3.21 & 1.28 & 3.38 & 3.05 & 3.53 & 2.89 & 0.01 \\
\hline Narcissism (N) & 1.28 & .65 & 1.44 & 1.15 & 1.40 & 1.16 & 0.05 \\
\hline Impulsivity (I) & 2.03 & .74 & 2.21 & 1.96 & 1.98 & 2.09 & 0.10 \\
\hline Total APSD score & 6.52 & 3.73 & 7.03 & 6.06 & 7.91 & 6.14 & 0.01 \\
\hline
\end{tabular}

$S D$ - standard deviation; ${ }^{\text {a }} \mathrm{N}=9,415 ;{ }^{\mathrm{b}} \mathrm{N}=4,808 ;{ }^{\mathrm{c}} \mathrm{N}=4,607 ;{ }^{\text {d }} \mathrm{N}=3,994 ;{ }^{\text {e }} \mathrm{N}=5,421$

Table 2 shows the means and standard deviation values of APSD variables with regard to gender and social milieu. Interestingly, in this study, the level and distribution of psychopathic traits, as measured by the teacher-report APSD scale, appeared relatively low. The results indicated that Polish boys had higher levels of callous-unemotional traits $(\mathrm{M}=3.38)$, narcissism $(\mathrm{M}=1.44)$ and impulsivity $(\mathrm{M}=2.21)$ than girls $(\mathrm{M}=3.05) ; 1.15$ and 1.86, respectively). Both APSD total and subscale scores remained significantly related to gender and social milieu. Urban adolescents scored higher on most of the APSD subscales. The differences were statistically significant, with the exception of impulsivity subscale $(\mathrm{p}>0.05)$.

Table 3. Clinically significant scores according to social milieu (numbers and percentages of subjects by subscale)

\begin{tabular}{|c|c|c|c|c|c|c|c|c|c|c|}
\hline \multirow{3}{*}{ APSD } & \multicolumn{4}{|c|}{ Below cut-off score } & \multicolumn{4}{|c|}{ Above cut-off score } & \multirow{2}{*}{\multicolumn{2}{|c|}{$\begin{array}{c}2 \text { versus } 1 \\
\text { comparison }\end{array}$}} \\
\hline & \multicolumn{2}{|c|}{ Urban } & \multicolumn{2}{|c|}{ Rural } & \multicolumn{2}{|c|}{ Urban $^{1}$} & \multicolumn{2}{|c|}{ Rural $^{2}$} & & \\
\hline & $\mathrm{N}$ & $\%$ & $\mathrm{~N}$ & $\%$ & $\mathrm{~N}$ & $\%$ & $\mathrm{~N}$ & $\%$ & $z$ test & $P$ \\
\hline CU & 3,786 & 94.79 & 5,254 & 96.92 & 208 & 5.21 & 167 & 3.08 & 1.98 & 0.05 \\
\hline $\mathrm{N}$ & 3,684 & 92.24 & 5,216 & 96.22 & 310 & 7.76 & 205 & 3.78 & 2.17 & 0.03 \\
\hline & 3,547 & 88.81 & 4,812 & 88.77 & 447 & 11.19 & 609 & 11.23 & 0.48 & 0.62 \\
\hline otal & 3,856 & 96.55 & 5,306 & 97.88 & 138 & 3.45 & 115 & 2.12 & 2.04 & 0.05 \\
\hline
\end{tabular}

Table 3 compares numbers and percentages of adolescents belonging to subgroups differing by level of displayed psychopathic traits. In total, out of 9,415 adolescents being assessed by their teachers, only 253 persons (2.68\%) displayed clinically significant traits of psychopathic disorder. In the subgroup with high intensity of psychopathic traits (above cut-off score of 25 points), there was a majority of adolescents from the urban social milieu. Among them, 3.45\% scored at or above 25 points in the total APSD scale, while only $2.12 \%$ of adolescents from the rural milieu scored at this level $(\mathrm{p}<0.05)$. Similar differences appeared in subsequent APSD subscales. The impulsivity subscale was the only one with no significant difference between urban and rural adolescents 
( $\mathrm{p}>0.05)$. This comparative analysis shows that the urban social environment seems to be more hazardous than rural in terms of the development of psychopathic traits in children and adolescents.

Table 4. Comparison of ASPD scores with Hong Kong (China) and US samples

\begin{tabular}{lcccccc}
\hline \multirow{2}{*}{ APSD scores } & \multicolumn{2}{c}{ Poland } & \multicolumn{2}{c}{ Hong Kong } & \multicolumn{2}{c}{ United States } \\
\cline { 2 - 7 } & Mean & SD & Mean & SD & Mean & SD \\
\hline Boys a & & & & & & \\
Callous/unemotional & 3.38 & 1.86 & 5.26 & 2.29 & 2.66 & 2.16 \\
Narcissism & 1.44 & 0.75 & 4.58 & 2.79 & 3.17 & 2.55 \\
Impulsivity & 2.21 & 1.14 & 3.49 & 2.12 & 4.47 & 2.01 \\
Total & 7.03 & 3.06 & 13.34 & 4.55 & 10.70 & 5.79 \\
\hline Girls ${ }^{\text {b }}$ & & & & & & \\
Callous/unemotional & 3.05 & 1.22 & 5.01 & 2.04 & 2.20 & 2.09 \\
Narcissism & 1.15 & 0.55 & 4.23 & 2.63 & 2.64 & 2.42 \\
Impulsivity & 1.86 & 0.72 & 3.46 & 1.94 & 3.58 & 1.86 \\
Total & 6.06 & 2.47 & 12.69 & 4.31 & 8.79 & 5.63 \\
\hline Fullc & & & & & & \\
Callous/unemotional & 3.21 & 1.28 & 5.14 & 2.18 & 2.43 & 2.13 \\
Narcissism & 1.28 & 0.65 & 4.42 & 2.72 & 2.90 & 2.49 \\
Impulsivity & 2.03 & 0.74 & 3.74 & 2.04 & 4.01 & 1.99 \\
Total & 6.52 & 3.73 & 13.03 & 4.45 & 9.79 & 5.79
\end{tabular}

Note: American sample sizes fluctuate due to missing data

a - sample, $\mathrm{N}=4,808 ;$ Hong Kong, $\mathrm{N}=1,948 ;$ United States, $\mathrm{N}=392-406$

b - Polish sample, $\mathrm{N}=4,607 ;$ Hong Kong, $\mathrm{N}=1,727 ;$ United States, $\mathrm{N}=430-444$

c Polish sample, $\mathrm{N}=9,415 ;$; Hong Kong, $\mathrm{N}=3,675 ;$ United States, $\mathrm{N}=829-857$

Table 4 presents comparisons of the APSD scores between Polish, Chinese (Hong Kong) and American secondary school students. The Chinese sample consisted of 3,675 students [23], while American sample included over 800 persons [11]. Differences between the 3 countries ranged from small to large, depending on the gender or subscales: Polish adolescents generally scored lower than their Chinese and American counterparts, both in total APSD scores, and in each particular subscales; for example, Hong Kong boys scored 13.34 on the total APSD scale, while boys from Poland scored 7.03.

More complex differences were observed in scores related to subsequent subscales: among boys, the largest score on the CU subscale occurred in the Hong Kong sample (5.26); in this subscale, Polish boys scored higher (3.38) than American boys (2.66); Hong Kong boys also seemed to be more narcissistic (4.58) than their American (3.17) and Polish (1.44) colleagues. Similar differences between the scores representing subsequent subscales occurred in groups of girls: Hong Kong girls scored higher (5.01) than Polish (3.05) and American girls (2.20) on the CU subscale; they also appeared more impulsive and narcissistic than their Polish and American counterparts.

\section{DISCUSSION}

As stated earlier, at present there are no solid data on the prevalence of psychopathic disorders in the general population of children and adolescents. Approximate rates of psychopathy are related to special populations, such as adolescents involved with the criminal or psychiatric services. This lack of knowledge is a result of too little research on child and adolescent psychopathy in different social and cultural/ethnic settings. To the best of the knowledge of the authors of the presented study, this survey is the first large-scale study designed to explore the prevalence of psychopathic disorders in mainstream Polish adolescents. As expected, small, but significant gender differences were observed, with boys scoring higher than girls on $\mathrm{CU}$, narcissism and impulsivity traits. Furthermore, similar to observations covered in the authors' previous publication, gender differences in psychopathic traits increased with the age of the adolescents [23]. The results of quantitative analysis revealed a significant interrelation between social milieu and psychopathic traits: rural adolescents scored lower than their urban counterparts in total ASPD scores and subscales related to CU and narcissism traits. Impulsivity was the only subscale where rural adolescents scored higher. Data included in Table 3 additionally support this finding which reveals that only $2.12 \%$ of rural adolescents scored above the cut-off score of 25 points, which indicates a clinically important intensity of psychopathic traits. In contrast, $3.45 \%$ adolescents from urban settings scored 25 points or higher. In this case the difference was statistically significant $(p<0.05)$.

Finally, comparison of the results of this study with the mean scores obtained in similar studies from Hong Kong and the USA, highlights some ethno-cultural differences in psychopathic traits. Although the size of differences ranged from small to large, the Hong Kong adolescents had clearly higher scores on the total APSD than Polish and American adolescents. This especially refers to $\mathrm{CU}$ and narcissism subscales. Polish adolescents also scored much lower than their American counterparts. Substantially higher scores of the Hong Kong adolescents on CU and narcissistic subscales seem to be an unexpected finding. One possible explanation is that the higher intensity of $\mathrm{CU}$ and narcissistic traits in Chinese adolescents may be due to different cultural meanings of basic traits included in the psychopathy concept. For example, in a previously conducted study, it was found that Chinese-Americans experience less emotion in reaction to both positive and negative effects of stimuli and report less variability in emotional experiences, compared to EuropeanAmericans [24]. It may also be true that the Chinese culture favours the suppression of emotional expression, which may result in higher ratings of unemotional symptoms on the APSD scale. The significantly lower scores on narcissism and CU traits found in Polish youth might also stem from different research settings. In the 3 compared populations, the APSD scale was used as the main research measure, but while the Polish adolescents were assessed by their teachers, in the Chinese and American studies the parent-report version of the scale was used.

Finally, it is recommended that future studies should focus on the origin of these social and cultural differences.

\section{CONCLUSIONS}

The results of the current study show that, in total, only a marginal part $(2.68 \%$; $\mathrm{N}=253)$ of the examined population of Polish adolescents demonstrated clinically significant symptoms of psychopathic disorder. It is especially true in relation to participants living in rural social milieu (2.12\%), compared to adolescents from the urban milieu who reached this level of psychopathology (3.45\%). Statistical analysis indicated that the difference between these subgroups is significant $(\mathrm{p}<0.05)$. This finding suggests that the urban social milieu, compared with the rural, should be considered 
as a risk factor for the development of psychopathic traits in children and adolescents. On the whole, the Polish participants scored much lower on total psychopathy scores than the Chinese (Hong Kong) and American adolescents. These differences pertained especially to such psychopathic features as callousness-unemotionality and narcissism.

The main strength of this study is its comprehensive large-scale nature. Although it was difficult to estimate the representativeness of the whole sample, its size allows for some generalizations. The authors hope that this research, being the first large-scale study carried out in to-date in Poland, constitutes an important contribution to the knowledge on epidemiology of psychopathic disorders in mainstream adolescents, especially those who are students of secondary schools. In Poland, as is widely known, adolescents attending gymnasiums have a reputation of being 'trouble-makers'.

On the other hand, some clear limitations of the study must be kept in mind. Firstly, the research relies on teacher informant ratings as a means of identifying the subjects presenting psychopathic features. It seems obvious that reliance on one source of information in this study, as in any other study, potentially excludes important information from other possible sources, such as parents and peers. Secondly, the concept of 'psychopathy' has not been fully established in medical diagnosis, and its applicability to immature persons requires further studies.

Despite its obvious limitations, the presented study indicates that the assessment of psychopathy in adolescents is a very important field of research, because our knowledge on the subject, stability and consequences of juvenile psychopathy, is still limited. Adult psychopathy is often described as an incurable disorder [25], and from this perspective it would be important and cost-effective to identify those at risk of psychopathic traits as early as possible. Faster recognition of children and adolescents with psychopathic traits would be beneficial for effective prevention and treatment efforts. The authors are convinced that this kind of study with a large community population of adolescents should be replicated in other East European countries, such as Hungary, Romania, Slovakia and Ukraine. Such epidemiological research has a number of benefits, for example, early identification of high-risk offenders in various socio-cultural settings, and examination of psychopathic traits in relation to potential etiological factors, longitudinal course and response to treatment approaches used in different countries.

\section{Acknowledgments}

The authors thank the Podkarpackie Educational Authority (Podkarpackie Kuratorium Oświaty), principals and teachers of all the involved schools for their kind cooperation in conducting this study.

\section{REFERENCES}

1. Cooke D, Mitchie C. Refining the construct of psychopathy: towards a hierarchical model. Psychol Assessment. 2001; 13: 171-188.

2. Hare RD. Without conscience: the disturbing world of the psychopaths among us. New York, Guilford, 2003.

3. Petrunik M, Weisman R. Constructing Joseph Fredricks: Competing narratives of a child sex murderer. Int J Law Psychiat. 2005; 28: 75-96.

4. Blair RJR. The emergence of psychopathy: Implications for the neuropsychological approach to developmental disorders. Cognition 2006; 101: 414-442.

5. Hare RD. The Hare Psychopathy Checklist-Revised. Multi Health Systems, Toronto, 2001.

6. Seagrave D, Grisso T. Adolescent development and the measurement of juvenile psychopathy. Law Hum Behav. 2002; 26:219-239.

7. Forth AE, Burke HC. Psychopathy in adolescence: assessment, violence and developmental precursors. In Psychopathy: Theory, Research and Implications for Society (eds D. Cooke, A. Forth \& R. Hare), pp. 205-230. Kluwer: Dordrecht, 1998.

8. Brandt JR et al. Assessment of psychopathy in a population of incarcerated adolescent offenders. Psychol Assessment 1997; 9: 429-435.

9. Hare RD. Psychopathy, affect and behavior. In: Cooke D, Forth A, Hare R. Psychopathy: Theory, Research and Implications for Society, pp. 105-139. Kluwer, Dordrecht, 1998.

10. Coid J, Yang M, Ullrich S, Roberts A, Hare RD. Prevalence and correlates of psychopathic traits in the household population of Great Britain. Int J Law Psychiatr. 2009; 32, 2: 65-73.

11. Frick PJ, Hare RD. The Antisocial Process Screening Device (APSD). Multi-Health Systems, Toronto, 2001.

12. Fung MT, Raine A, Loeber R, et al. Reduced electrodermal activity in psychopathy-prone adolescents. J Abn Psychol. 2005; 114: 187-196.

13. Johnstone L, Cooke DJ. Psychopathic-like traits in childhood: Conceptual and measurement concerns. Behav Sci Law 2004; 22:103125.

14. Barry CT, Frick PJ, Grooms T, McCoy MG, Ellis ML, Loney BR. The importance of callous-unemotional traits for extending the concept of psychopathy to children. J Abnorm Psychol. 2000; 109: 335-340.

15. Munõz LC, Frick PJ. The reliability, stability, and predictive utility of the self-report version of the antisocial process screening device. Scand J Psychol. 2007; 48: 299-312.

16. Kotler JS, McMahon RJ. Child psychopathy: theories, measurement, and relations with the development and persistence of conduct problems. Clin Child Family Psychol Rev. 2005; 8(4): 291-325

17. Sharp C, Kine S. The assessment of juvenile psychopathy: strengths and weaknesses of currently used questionnaire measures. Child Adolesc Ment Health 2008; 13(2): 85-95.

18. Marsh A, Finger E, Mitchell D, Ried M, Sims C, Kosson D et al. Reduced amygdala response to fearful expressions in children and adolescents with callous-unemotional traits and disruptive behavior disorders. Am J Psychiatry 2008; 165: 712-720.

19. Budhani S, Blair R. Response reversal and children with psychopathic tendencies: Success is a function of salience of contingency change. J Child Psychol Psychiatr. 2005; 46: 972-981.

20. Vitale JE, Newman JP, Bates JE, Goodnight J, Dodge K, Pettit G. Deficient behavioural inhibition and anomalous selective attention in a community sample of adolescents with psychopathic traits and lowanxiety traits. J Abnorm Child Psychol. 2005; 33:461-470.

21. Brislin RW. Back-translation for cross-cultural research. J Cross Cult Psychol. 1970; 1: 185-216.

22. Perenc L, Radochoński M. Psychopathic traits and reactive-proactive aggression in a large community sample of Polish adolescents. Child Psychiatry Hum Dev. 2013; DOI 10.1007/s10578-013-0432-4 (published on-line; open access).

23. Fung AL, Gao Y, Raine A. The utility of the child and adolescent psychopathy construct in Hong Kong, China. J Clin Child Adolesc Psychol. 2010; 39(1):134-140.

24. Tsai JL, Levenson RW. Cultural influences on emotional responding: Chinese American and European American dating couples during interpersonal conflict. J Cross Cult Psychol. 1997; 28: 600-625.

25. Salekin R. Psychopathy and therapeutic pessimism: Clinical lore or clinical reality? Clin Psychol Rev. 2002; 22: 79-112. 